\title{
Ecologist sues over wrecked iguana study
}

\section{John Whitfield, London}

An ecologist whose studies of marine iguanas in the Galapagos Islands were damaged by an oil spill is suing the oil tanker's owner and insurer.

Martin Wikelski of Princeton University in New Jersey is seeking US\$600,000 in damages as part of a wider, \$14-million claim being made by the Galapagos National Park against the master, owners and insurers of the Jessica, a tanker that ran aground on the island of San Cristóbal in January 2001. The park is also suing Petrocomercial, an arm of the Ecuadorian state oil company, which owned the oil.

Wikelski has been studying the Galapagos' marine iguanas since 1987. His work has revealed, for example, how the animals' bodies shrink in response to El Niño events (see Nature 403,37-38;2000). But after the oil spill, the focus of his observations switched sharply from evolution to pollution.

Following the accident, Wikelski and his colleagues monitored the iguanas at an oil-affected site and at one that had escaped

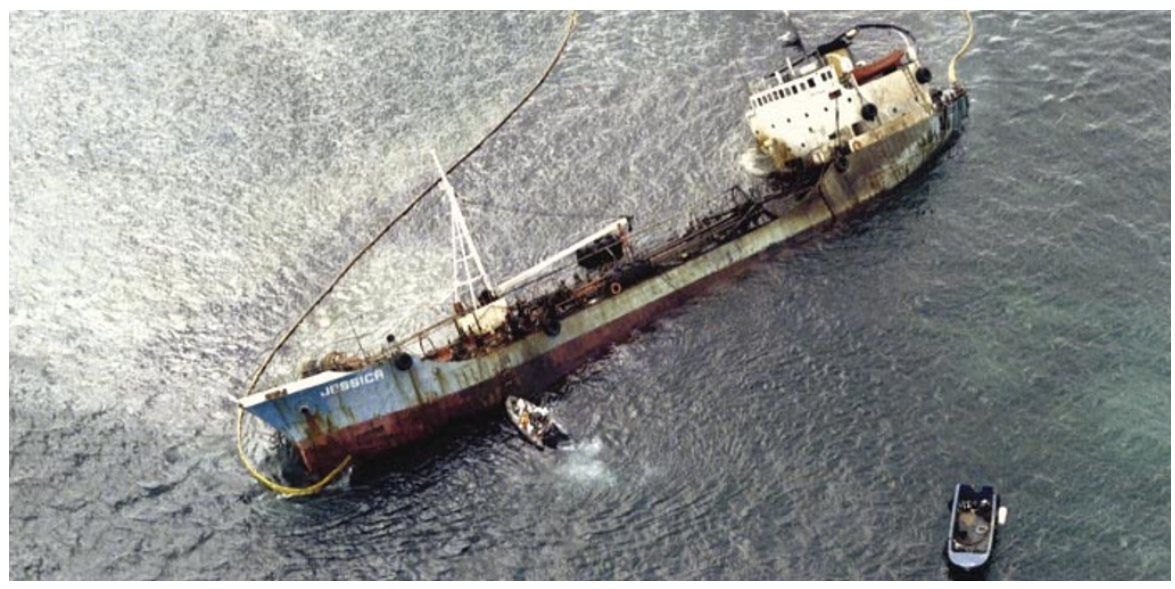

Black death: oil from the Jessica has killed a large number of marine iguanas on San Cristóbal island.

contamination. In this week's Nature, they report that by December 2001 more than $60 \%$ of the marked iguanas at the contaminated site had died, compared with none at the site that escaped pollution (Nature 417, $607-608 ; 2002$ ).

The team suggests that small amounts of

\section{Merger plans rattle bones in Berlin}

\section{Johanna Schwarz, Munich}

Palaeontologists at Berlin's Museum of Natural History are up in arms over a reform plan that they fear could leave the dinosaur discipline on the edge of local extinction.

An outside panel of experts recommended in April that the institutes of palaeontology, mineralogy and zoology at the museum should merge into a single department, with one director.

But palaeontologists at the institute claim that the panel's report belittled their discipline. The report describes palaeontology as having "no scientific autonomy". It adds that the discipline lacks a theoretical approach as it is derived from the objects it studies and relies on "expeditions and preparation techniques".

"Palaeontology is definitely hard science," says Rainer Schoch, one of 15 palaeontologists at the museum, who says he finds the report's findings "unacceptable".

Hans-Peter Schultze, the museum's head of palaeontology, says that the proposed merger could mark the end of serious palaeontological research there, leaving behind only technicians to look after the fossil collection - one of the largest in Europe.

Schultze, who retires next year, also complains that there were no palaeontologists on the eight-strong panel. Alfred Crompton of the Museum of Comparative Zoology at Harvard University, a palaeontologist who was supposed to represent the field, could not take part because no funds were available for him to travel to Berlin.

Gerhard Neuweiler, a zoologist at the University of Munich, former president of Germany's science council and a member of the panel, defends its findings. "We have not questioned the quality of palaeontological research at the museum," he says. Fears that it could be ended are unjustified, he adds.

But palaeontology is already in decline at several German institutes. The universities of Marburg, Darmstadt, Giessen and Mainz, for example, no longer offer courses in palaeontology or fill vacant positions.
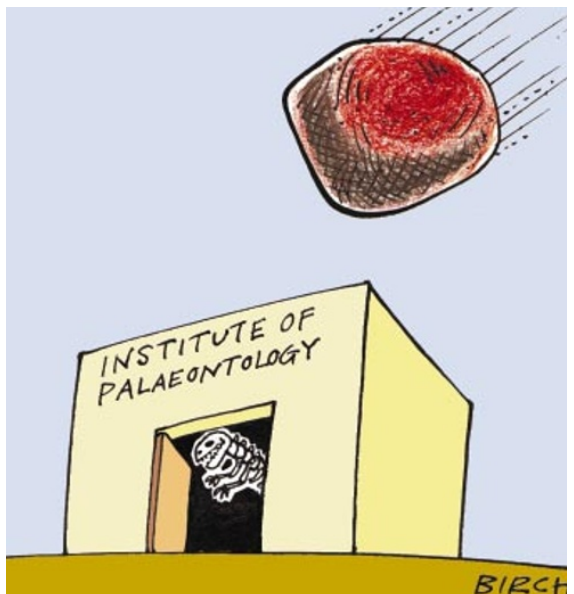

oil killed microbes in the iguanas' guts that enable the animals to digest algae, causing them to starve. "Even a tiny amount of oil in the water can be very harmful," says Wikelski.

The spill terminated Wikelski's earlier experiments, and the $\$ 600,000$ represents some of the funding that Wikelski and his team had received for them from Germany's Max Planck Society, the University of Princeton and the US National Science Foundation.

The rest of the \$14-million claim covers the cost of cleaning up the spill and monitoring its effects, loss of tourism and fishing revenue, and damage to the Galapagos' pristine image. "We're still feeling the economic effects," says park biologist Mauricio Velasquez.

The case was filed with the High Court at Guayaquil, Ecuador, where hearings began this February. Terra Nova, the Londonbased insurer of the Jessica, is contesting the right of the Ecuadorian courts to hear it. The insurer also says that the Jessica was uninsured when it ran aground because the ship's owners had not paid their premiums and had not complied with the terms of their policy. "We're just not involved at all," says Andrew Barker, an underwriter with the company. Petrocomercial declined to comment on the case.

But Ider Valverde, the leader of the park's legal team, says that the insurer is liable because it failed to notify the authorities that the Jessica was no longer covered, as is required by Ecuadorian law.

"We have made it very clear that the park is a non-profit organization, and have tried several times to settle with the insurers in an amicable fashion," says Valverde. "I imagined that they would have preferred a nice quiet settlement, but they have decided to litigate instead." If he wins, Wikelski says that any damages will be used to set up a fund to support young Ecuadorian scientists. 